\title{
RESEARCH
}

Open Access

\section{Effect of a physical activity and sleep m- health intervention on a composite activity- sleep behaviour score and mental health: a mediation analysis of two randomised controlled trials}

Mitch J. Duncan ${ }^{1,2^{*}}$ (D), Anna T. Rayward ${ }^{1,3}$, Elizabeth G. Holliday ${ }^{1}$, Wendy J. Brown ${ }^{4}$, Corneel Vandelanotte ${ }^{5}$, Beatrice Murawski ${ }^{1,2}$ and Ronald C. Plotnikoff ${ }^{1,3}$

\begin{abstract}
Background: To examine if a composite activity-sleep behaviour index (ASI) mediates the effects of a combined physical activity and sleep intervention on symptoms of depression, anxiety, or stress, quality of life (QOL), energy and fatigue in adults.

Methods: This analysis used data pooled from two studies: Synergy and Refresh. Synergy: Physically inactive adults (18-65 years) who reported poor sleep quality were recruited for a two-arm Randomised Controlled Trial (RCT) (Physical Activity and Sleep Health (PAS; $n=80)$, or Wait-list Control (CON; $n=80)$ groups). Refresh: Physically inactive adults (40-65 years) who reported poor sleep quality were recruited for a three-arm RCT (PAS $(n=110)$, Sleep Health-Only (SO; $n=110)$ or CON $(n=55)$ groups). The SO group was omitted from this study. The PAS groups received a pedometer, and accessed a smartphone/tablet "app" using behaviour change strategies (e.g., selfmonitoring, goal setting, action planning), with additional email/SMS support. The ASI score comprised selfreported moderate-to-vigorous-intensity physical activity, resistance training, sitting time, sleep duration, efficiency, quality and timing. Outcomes were assessed using DASS-21 (depression, anxiety, stress), SF-12 (QOL-physical, QOLmental) and SF-36 (Energy \& Fatigue). Assessments were conducted at baseline, 3 months (primary time-point), and 6 months. Mediation effects were examined using Structural Equation Modelling and the product of coefficients approach (AB), with significance set at 0.05 .

(Continued on next page)
\end{abstract}

\footnotetext{
* Correspondence: Mitch.Duncan@newcastle.edu.au

'School of Medicine \& Public Health; Faculty of Health and Medicine, Priority

Research Centre for Physical Activity and Nutrition, The University of

Newcastle, University Drive, Callaghan, NSW 2308, Australia

${ }^{2}$ Priority Research Centre for Physical Activity and Nutrition, The University of Newcastle, University Drive, Callaghan, NSW 2308, Australia

Full list of author information is available at the end of the article
}

(c) The Author(s). 2021 Open Access This article is licensed under a Creative Commons Attribution 4.0 International License, which permits use, sharing, adaptation, distribution and reproduction in any medium or format, as long as you give appropriate credit to the original author(s) and the source, provide a link to the Creative Commons licence, and indicate if changes were made. The images or other third party material in this article are included in the article's Creative Commons licence, unless indicated otherwise in a credit line to the material. If material is not included in the article's Creative Commons licence and your intended use is not permitted by statutory regulation or exceeds the permitted use, you will need to obtain permission directly from the copyright holder. To view a copy of this licence, visit http://creativecommons.org/licenses/by/4.0/. The Creative Commons Public Domain Dedication waiver (http://creativecommons.org/publicdomain/zero/1.0/) applies to the data made available in this article, unless otherwise stated in a credit line to the data. 
(Continued from previous page)

Results: At 3 months there were no direct intervention effects on mental health, QOL or energy and fatigue (all $p>0.05$ ), and the intervention significantly improved the ASI (all $p<0.05$ ). A more favourable ASI score was associated with improved symptoms of depression, anxiety, stress, QOL-mental and of energy and fatigue (all $p<0.05)$. The intervention effects on symptoms of depression $([\mathrm{AB} ; 95 \% \mathrm{Cl}]-0.31 ;-0.60,-0.11)$, anxiety $(-0.11$; $-0.27,-0.01)$, stress $(-0.37 ;-0.65,-0.174)$, QOL-mental $(0.53 ; 0.22,1.01)$ and ratings of energy and fatigue $(0.85 ; 0.33$, 1.63) were mediated by ASI. At 6 months the magnitude of association was larger although the overall pattern of results remained similar.

Conclusions: Improvements in the overall physical activity and sleep behaviours of adults partially mediated the intervention effects on mental health and quality of life outcomes. This highlights the potential benefit of improving the overall pattern of physical activity and sleep on these outcomes.

Trial registration: Australian New Zealand Clinical Trial Registry: ACTRN12617000680369; ACTRN12617000376347. Universal Trial number: U1111-1194-2680; U1111-1186-6588. Human Research Ethics Committee Approval: H-20160267; H-2016-0181.

Keywords: Physical activity, Sitting, Resistance training, Sleep quality, Sleep health, Depression, Anxiety, Stress, Mediation, Quality of life

\section{Introduction}

It is well established that regular participation in physical activity improves mental well-being, and reduces the risk of several chronic diseases and all-cause mortality [1, 2]. There is also robust evidence that adults who obtain 7$9 \mathrm{~h}$ of sleep per day have reduced risk of these same health outcomes $[3,4]$. It is estimated that between 20 and $30 \%$ of Australian adults engage in a pattern of physical activity and sleep characterised by low levels of physical activity, short sleep duration and poor sleep quality $[5,6]$. Physical activity and sleep can jointly influence health [6-8], though few studies to date have examined how different combinations or patterns of these behaviours influence health outcomes $[4,9,10]$. Consequently, there is a need to better understand how physical activity and sleep jointly influence health outcomes [3].

Much of the evidence to date has derived from prospective cohort studies that examined association between different combinations of physical activity and sleep duration and all-cause mortality [4, 10]. These studies used varying thresholds to classify physical inactivity (e.g., < $1 \mathrm{~h} /$ day, < $450 \mathrm{MET} \mathrm{min} / \mathrm{wk}$ ) and sleep duration (e.g., $<6 \mathrm{~h} /$ day, $<7 \mathrm{~h} /$ day) which limits the potential for direct comparison. However, both studies observed that participants classified as the least physically active, who also reported short sleep duration, had a significantly increased risk of all-cause and cardiovascular mortality, relative to participants classified as the most physically active who also reported mid-range sleep duration [4, 10]. Keadle and colleagues [9] extended these studies [4, 10] that examined activity-sleep dyads (i.e., duration of activity and sleep, activity duration and sleep quality) by using a behaviour index comprised of multiple indicators of physical activity (i.e., volume of light, moderate- and vigorous-intensity physical activity, duration of sitting time, frequency of resistance training) and sleep duration. Relative to participants with the lowest quintile, participants classified in the highest quintile (indicating a more favourable overall pattern of these behaviours) had a significantly lower risk of all-cause (Hazard Ratio $(\mathrm{HR})=0.53$ ) and cardiovascular mortality $(\mathrm{HR}=0.42)$ [9]. These observations highlight the potential benefit of interventions that aim to improve the overall pattern of activity and sleep and subsequently improve health outcomes, although to date it is unclear how changes in activitysleep behaviours during an intervention influence health outcomes.

Physical activity and sleep health can be described using multiple dimensions of each behaviour (i.e., sedentary behaviour, activity frequency, intensity, type, duration; duration, quality, timing and restorative effects of sleep [11]). This approach may better capture the overall pattern of each behaviour. This is important as several studies report that different patterns of activity (i.e., moderate to vigorous intensity physical activity (MVPA) and resistance training [12]) or sleep (i.e., sleep duration and quality [13]) influence physical (i.e., cardiometabolic health) and mental health (i.e., depressive, anxiety) in different ways $[6,14,15]$. However, we are unaware of studies that have examined how changes in physical activity and sleep jointly influence health using multiple dimensions to represent each behaviour.

Multiple behaviour interventions that specifically target changes in both physical activity and sleep provide the opportunity to examine how changes in these behaviours are associated with health outcomes. Unlike the multitude of interventions that target changes 
in either physical activity [16-18] or sleep (i.e., targeting improvements in insomnia symptoms) $[19,20]$ there are few published interventions that have specifically targeted changes in both physical activity and sleep [21-25]. Although some interventions target other behaviours (e.g., diet [24, 25], or PAP use [23]) that make them unsuitable to pool with studies that only target activity and sleep. The Synergy and Refresh trials were separate studies that used the "Balanced" mobile health platform (m-health) to deliver a common combined physical activity and sleep intervention in two separate populations (See methods for further details). The rationale, methods and primary outcomes of these studies were described elsewhere $[21,22,26,27]$. The current study pooled data from these studies to maximise statistical power and examine how intervention effects on mental health are mediated by changes in the overall patterns of physical activity and sleep.

Therefore, the aims of this study were to examine 1) the effects of a combined physical activity and sleep $\mathrm{m}$-health intervention on a behavioural index (activity-sleep index) composed of multiple dimensions of physical activity and sleep health, 2) the effects of a m-health intervention on quality of life, ratings of energy and fatigue, and symptoms of depression, anxiety and stress, 3) how the behavioural index mediates the effects of a m-health intervention on these outcomes (See Fig. 1).

\section{Methods}

\section{Study design}

Data for this study were pooled from two separate Randomised Controlled Trials (RCT) of a m-health intervention, which was designed to improve physical activity and sleep health behaviours of physically inactive adults with poor sleep quality without a sleep disorder [21, 22]. The rationale, study protocol and design, and main outcomes of each trial are described elsewhere [21, 22, 26, 27]. Commonalties between the two studies in the physical activity and sleep health intervention, control group, outcomes assessed and assessment methods used allowed for data to be pooled for the current study as described below. Details of the inclusion and exclusion criteria specific to each study are provided in Supplementary Table 1 and summarised here. Participants were eligible if they were aged 18-55 years (Synergy Study) or 45-65 years (Refresh Study), lived in Australia, reported $<90$ min of moderate to vigorous intensity physical activity in the last week, and rated their sleep quality as fairly bad or very bad. Exclusion criteria included employed in shift-work, diagnosed sleep disorder, current use of a device to track activity or sleep [21, 22]. The study design and intervention components used in each trial are shown in Supplementary Table 1.

Both studies recruited participants using primarily social media advertising. Briefly, the aim of the Synergy Study was to compare the efficacy of a combined physical activity and sleep health intervention with a wait-list

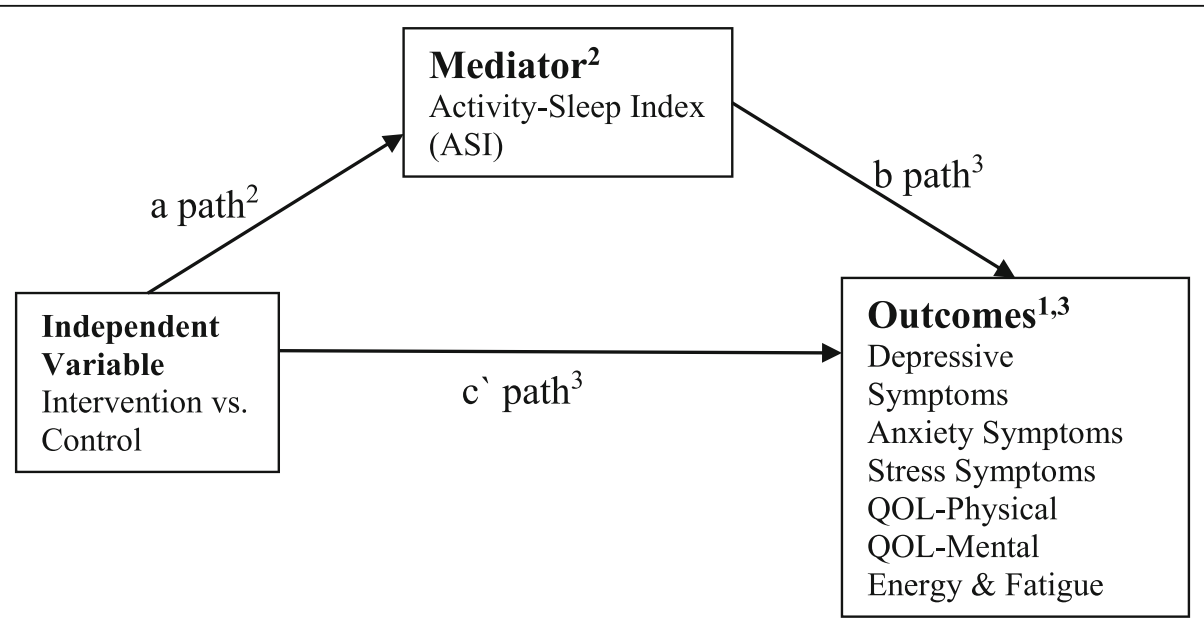

Notes: 1. All outcomes examined in separate mediation models at 3 and 6 months. 2. Analyses examining the a path were adjusted for the baseline value of the mediator, and study (Refresh, Synergy). 3 . Analyses examining the $b$ path, $c^{\prime}$ were adjusted for baseline value of the mediator, study (Refresh, Synergy) and the outcome.

Fig. 1 Overview of mediation model 
control [21, 26]. Participants $(n=160$; mean age: 41.5 ( $\mathrm{SD}=9.9) ; 80 \%$ female) were recruited between JuneAugust 2017 and the study was conducted between June 2017 and February 2018. The aim of the Refresh Study was to compare the efficacy of a combined physical activity and sleep health intervention with a sleep health-only intervention and a wait-list control $[22,27]$. Participants $(n=275$; mean age: $52.0(\mathrm{SD}=6.9)$; $83 \%$ female) were recruited between May-September 2017 and the study was conducted between June 2017 and March 2018. The combined physical activity and sleep health intervention in both trials was the same, in regards to mode of delivery, theoretical basis, educational content, and behaviour change techniques used. The sleep health-only intervention in Refresh included the same sleep health content as the combined group, but this group did not receive any intervention content or material about physical activity beyond that provided in sleep hygiene materials (e.g., being physically active can help improve sleep). Data from this arm $(n=110)$ were therefore omitted from the current study to allow direct comparison of a combined physical activity and sleep health intervention to a control group. Both studies conducted online assessments at baseline, 3 months and 6 months, were prospectively registered with the Australian and New Zealand Clinical Trials Registry and received ethical approval (H-2016-0181, H-2016-0267) at the University of Newcastle. Participants in both trials provided informed consent. Each study used computer generated permuted block randomisation to develop the randomisation sequence, with group allocation concealed in sequentially numbered envelopes. Participants were not blinded to group allocation given the nature of the interventions. At the request of the reviewers, a researcher not involved in the current study conducted a risk of bias assessment on each trial separately using the Cochrane ROB 2.0 instrument [28]. This indicates a low risk of bias overall for all domains except the measurement of the outcome (some concerns) due to participant self-reported outcomes. (see Supplementary Table 8).

\section{Interventions}

The combined physical activity and sleep (PAS) intervention groups ( $n=190$ (Synergy: $n=80+$ Refresh: $n=$ 110)) received access to a specifically designed app ("Balanced") developed by the investigators, which provided a platform for implementation of key behaviourchange techniques, including self-monitoring, goal setting and feedback, that have been shown to be effective $[29,30]$. Detailed description of the intervention is provided elsewhere [21, 22, 26, 27] and is summarised in Supplementary Tables 1 and 1a. Participants used the app for goal setting and action planning to increase their physical activity (i.e., MVPA, step counts and resistance training) and to improve their sleep quality and sleep behaviours (stabilising bed/wake times, sleep hygiene behaviours and stress management (e.g., progressive muscle relaxation, deep breathing exercises, mindfulness). Participants were mailed a participant handbook, containing an app installation/user guide, "tools" including strategies for stress management, goal setting and action planning (followed up with a monthly electronic copy). Weekly summaries of physical activity and sleep behaviours and progress in relation to goals, based on app entries, were emailed to participants during the 3month intervention period. Weekly educational facts were sent via text message, and text message prompts to re-engage with self-monitoring were sent if required. Wait-list control participants $(n=135$ (Synergy; $n=80$; Refresh; $n=55)$ ) were offered full access to the intervention after the 6-month assessment.

\section{Measures \\ Mediators}

Participants completed all online assessments using the Qualtrics survey platform at baseline, 3 months and 6 months post baseline. Sociodemographic variables (e.g., age, gender, education, chronic disease status, height and weight to calculate BMI) were assessed at baseline. The frequency (sessions/wk) and duration of moderate-to vigorous-intensity physical activity (minutes/wk) were measured using the Active Australia Questionnaire which assesses time spent walking, and in moderate- and vigorous-intensity activities during the previous 7 days [31-34]. The concurrent validity of the Active Australia Questionnaire compared to accelerometer measures of activity and test retest reliability are similar to those of other self-report instruments [31-34]. The frequency of resistance training (sessions/wk) was measured using a single item asking participants about the number of days/wk. they engaged in resistance training [21, 27]. This item has been used to assess changes in the frequency of resistance training in previous studies [21, 27]. Duration of daily sitting time (min/day) was measured using the Workforce Sitting Questionnaire, which assesses total and domain-specific time spent sitting on work-days and non-workdays [35], and has acceptable measurement properties [35]. Sleep satisfaction, daytime alertness, sleep timing, efficiency and duration were assessed using the Pittsburgh Sleep Quality Index (PSQI), which is a valid and reliable measure of sleep quality [36]. The PSQI has acceptable psychometric properties in populations, both, with and without clinical sleep disturbances [37]. The regularity of sleep was assessed using two items from the Sleep Hygiene Index, which has acceptable psychometric properties [38]. 


\section{Activity sleep index}

Consistent with the aims of the study, an activity-sleep index (ASI) was created to summarise the multiple dimensions of physical activity and sleep health. The ASI included 12 dimensions: six physical activity dimensions based on the frequency, duration, intensity and type of physical activity, and six sleep health dimensions based on the definition of sleep health [11,39-41]. The specific items, responses, and scoring for the ASI and provided in Supplementary Table 2. The items are briefly summarised here:

1. Frequency-MVPA (Number of sessions of MVPA/wk),

2. Frequency-RT (Number of days of resistance training/wk),

3. Intensity (Proportion of MVPA that was vigorous in intensity),

4. Type (Participation in no MVPA or resistance training, either MVPA or resistance training, or both),

5. Time (Duration of MVPA/wk),

6. Sitting (Duration of sitting time/wk).

7. Daytime alertness (Trouble staying awake during the day),

8. Sleep Quality (Overall sleep quality rating),

9. Sleep Timing (Midpoint of sleep between 02:00 am and 04:00 am),

10. Sleep Regularity (Variability in bed and wake times),

11. Sleep Efficiency (Sleep efficiency ([sleep duration/ time in bed] $\times 100)$,

12. Sleep Duration (Meeting age-appropriate sleep duration guidelines).

Various approaches exist to combine multiple behaviours or metrics into a single index that include time (i.e., duration of activity, sleep duration) and non-time based metrics (i.e., frequency of activity, sleep quality, timing of sleep) with varying recall periods (i.e., weekly for activity, last month for sleep quality) [42, 43]. However, there currently is no consensus on the most appropriate method. Therefore, the current study used a simple approach that rescaled each dimension from 0 to 10 with high scores reflecting lower risk behaviour, then summed each of the dimensions to form the ASI-12 (score range 0-120) at each assessment point [44]. This approach provides scores on a fixed scale (e.g., 0-10 for each dimension, 0-120 overall) that can be easily compared between studies. The approach used to rescale the individual dimensions of the ASI was Rescaled score $=\left(\frac{\left(X-X_{\text {min }}\right)}{X_{\text {Range }}}\right) n$ where $\mathrm{X}$ is the observed value, $\mathrm{X}_{\min }$ is the minimum observed value of the original variable, $\mathrm{X}_{\text {Range }}$ is the difference between the minimum and maximum of the observed values, and $n$ is upper limit of the rescaled variable (e.g., $n=10)$. Each individual dimension score was rescaled using the observed minimum and maximum of the observed values over all assessment points.

As the overall pattern of activity and sleep may be of interest in other studies that may not assess such detailed measures of these behaviours, a second index score using only 6 dimensions was also created including dimensions $2,5,6,8,11$, and 12 , to create the ASI-6. These items were selected a priori based on the likelihood that other studies may include similar measures and also because of their utility to capture overall patterns of activity and sleep. The ASI- 6 was used in sensitivity analyses.

\section{Outcomes}

\section{Mental health and quality of life}

Symptoms of depression, anxiety and stress were assessed using the depression, anxiety and stress scale (DASS-21), which has adequate psychometric properties [45]. The DASS-21 has satisfactory levels of internal consistency for each of its individual scales of depression $(r=0.88)$, anxiety $(r=0.82)$ and stress $(r=0.90)$, with higher scores indicating more severe symptoms [46]. Health-related quality of life (HRQoL) was assessed using the 12-Item Short Form Health Survey which measures self-reported physical (QOL-Physical) and mental (QOL-Mental) health components over the previous four-week period $(\alpha=0.89,0.76$ QOL-Physical and QOL-Mental, respectively) [47, 48]. Ratings of energy and fatigue were measured using the 3-item subscale of the Rand-36 (Version 1.0) [49]. Higher scores on the QOL-Physical, QOL-Mental and RAND-36 energy and fatigue outcomes, indicate better outcomes [49].

\section{Statistical analysis}

The Synergy and Refresh trials were each powered based on their respective primary outcomes as reported elsewhere $[21,22,26,27]$. No a priori power calculations were conducted for the mediation analyses presented in this manuscript. Independent $\mathrm{t}$-tests (continuous data) and chi-square analyses (categorical data) were employed to test for differences in sample characteristics between survey completers and non-completers of the interventions. Survey non completers were defined as individuals who did not complete either the Active Australia Questionnaire or the PSQI at the 3 month assessment. Spearman's Rho was used to estimate correlations between the rescaled ASI-12 dimensions. To provide information regarding how the ASI-12 changed over time in response to the intervention, descriptive statistics were presented by group at each assessment point, and for the magnitude of differences between 
groups at 3 months and 6 months, differences were expressed using Cohen's d [50]. Exploratory analyses were conducted to compare change in ASI-12 from baseline to 3 months according to whether participants reported changes in severity of depression, anxiety, or stress symptoms or not. Change in symptom severity was classified as improvement (i.e., a reduction of at least one level of symptom severity score (i.e., from moderate to mild or normal)), or no change/worsening (i.e., no decrease or an increase in symptom score) [45].

Structural Equation Modelling was used to examine intervention effects on the ASI- 12 at 3 months, the intervention effects on the outcomes of mental health and quality of life at 3 months, and how the ASI-12 mediates the effects of a $\mathrm{m}$-health intervention on these outcomes at 3 months (Fig. 1). Figure 1 outlines the mediation model for each outcome. The a-path represents the effect of the intervention on the hypothesised mediator, the b-path represents the association between the mediator and the outcome variables and the $c^{\prime}$-path represents the direct effect of the intervention on the outcome. Mediation effects were estimated using a product-of-coefficients approach (denoted by $a^{*} b$ ) and the $95 \%$ confidence intervals of the $a b$ coefficient were estimated using bias-corrected bootstrapping on 5000 samples. The a-path was adjusted for the baseline value of the mediator, the b-path and c-paths were adjusted for baseline value of the outcome, all analyses included an indicator to adjust for study (i.e., Synergy, Refresh). Results are reported as unstandardised coefficients. Missing data at follow up was assumed to be missing at random as age and baseline values of each outcome were associated with the likelihood of the outcome missing. Full-information maximum likelihood (FIML) was used to handle missing data and include all available observations [51]. This same analysis approach was used to examine mediation effects at 6 months, and was repeated at 3 months and 6 months using the ASI- 6 . Assumptions of normality, outliers and homoscedasticity for each mediation path were examined using residual plots from multiple linear regression analysis, and no noticeable violations were observed. The assumption of no exposuremediator interaction was examined using linear regression and no significant interactions were observed. All analyses were conducted in Stata MP (15.1) using an alpha level of 0.05 to declare statistical significance.

\section{Results}

Of the 325 participants who completed the baseline survey, 276 (84.9\%) completed the 3-months survey (intervention group: $n=161$ (84.7\%); control group: $n=115$ $(85.2 \%))$. Participant flow through each trial is shown in Supplementary Figures 1 and 2 [21, 22]. Compared with completers, non-completers of the 3-month survey were significantly younger and had significantly higher depression and stress scores at baseline (Supplementary Table 3). Participants' baseline sociodemographic characteristics, mental health and health-related quality of life are shown in Table 1. On average, participants were aged 47 years (range 19 to 64 ), had a mean BMI of 28 , and $81.2 \%$ were female; the majority of participants reported symptoms of depression, anxiety or stress that were classified as normal.

Small to moderate magnitude correlations were observed between each of the ASI dimensions and also with the overall ASI-12 score (Supplementary Table 4). The ASI-12 score and ASI dimensions were similar in the intervention and control groups at baseline; higher scores were observed in the intervention group at 3 and 6 months relative to the control group (Table 2). The magnitude of between group differences in the overall ASI score at 3 and 6 months was moderate $(d=0.42-$ 0.51 ) and ranged from small to moderate for the individual ASI dimensions (Table 2).

\section{Mediation effects}

At 3 months, there were no direct effects of the intervention on any of the mental health or quality of life outcomes (c'-path, Table 3) but there were significant total effects (c-path, Table 3) of the intervention on symptoms of stress and ratings of energy and fatigue. As shown in Table 3 , the intervention significantly improved the ASI-12 at 3 months (a-path, Table 3). Higher levels (more favourable) of the ASI-12 score at 3 months were significantly associated with lower symptoms of depression, anxiety, stress, QOL mental health and ratings of energy and fatigue (b-path, Table 3). Mediation analyses revealed that the ASI-12 score significantly mediated the effects of the intervention on symptoms of depression, anxiety, stress, QOL mental health and ratings of energy and fatigue at 3 months (Table 3). The proportion of the intervention effect mediated by the ASI-12 was 55, 34, 5949 and 43\% for depression, anxiety, stress, QOL mental health and ratings of energy and fatigue respectively. At 6 months, the magnitude of associations was larger although the overall pattern of results was similar to that observed at 3 months (Table 4). Sensitivity analyses using the simpler ASI-6 revealed a similar pattern of results at both 3 and 6 months (Supplementary Tables 5 and 6).

\section{Discussion}

This study examined the effect of a combined physical activity and sleep intervention on a physical activitysleep index and how changes in the physical activitysleep index mediated changes the intervention effects on mental health and quality of life. The intervention significantly improved the physical activity-sleep index and 
Table 1 Summary of baseline sociodemographic and mental health characteristics of participants by control and intervention groups

\begin{tabular}{|c|c|c|c|}
\hline \multirow{3}{*}{$\overline{\text { Age (years) }}$} & \multirow{2}{*}{$\begin{array}{l}\text { Control } \\
N=135 \\
M(S D), n(\%)\end{array}$} & \multirow{2}{*}{$\begin{array}{l}\text { Intervention } \\
\mathrm{N}=190 \\
\mathrm{M}(\mathrm{SD}), \mathrm{n}(\%)\end{array}$} & \multirow{2}{*}{$\begin{array}{l}\text { Total } \\
N=325 \\
M(\text { (SD), n (\%) }\end{array}$} \\
\hline & & & \\
\hline & $46.2(10.4)$ & $47.2(9.7)$ & $46.8(10.0)$ \\
\hline \multicolumn{4}{|l|}{ Sex } \\
\hline male & $26(19.3 \%)$ & 35 (18.4\%) & $61(18.8 \%)$ \\
\hline female & 109 (80.7\%) & 155 (81.6\%) & $264(81.2 \%)$ \\
\hline Education (years) & $16.3(2.9)$ & $16.1(2.8)$ & $16.2(2.8)$ \\
\hline \multicolumn{4}{|l|}{ Occupation } \\
\hline Blue Collar & $5(3.7 \%)$ & $4(2.1 \%)$ & $9(2.8 \%)$ \\
\hline White Collar & $18(13.3 \%)$ & $37(19.5 \%)$ & 55 (16.9\%) \\
\hline Professional & $85(63.0 \%)$ & $107(56.3 \%)$ & $192(59.1 \%)$ \\
\hline Retired, Student, Home Duties, Other & $27(20.0 \%)$ & $42(22.1 \%)$ & $69(21.2 \%)$ \\
\hline \multicolumn{4}{|l|}{ Income/Yr } \\
\hline$\leq \$ 30,000$ & $32(23.7 \%)$ & $30(15.8 \%)$ & $62(19.1 \%)$ \\
\hline$\$ 30,001-\$ 50,000$ & $14(10.4 \%)$ & $26(13.7 \%)$ & $40(12.3 \%)$ \\
\hline$\$ 50,001-\$ 70,000$ & $26(19.3 \%)$ & 39 (20.5\%) & 65 (20.0\%) \\
\hline$\$ 70,001-\$ 100,000$ & $25(18.5 \%)$ & $47(24.7 \%)$ & $72(22.2 \%)$ \\
\hline$\geq \$ 100,001$ & $30(22.2 \%)$ & $30(15.8 \%)$ & $60(18.5 \%)$ \\
\hline don't know/prefer not to answer & $8(5.9 \%)$ & $18(9.5 \%)$ & $26(8.0 \%)$ \\
\hline BMI & $27.7(4.1)$ & $28.5(4.3)$ & $28.2(4.2)$ \\
\hline DASS-21 Depression & $11.5(8.5)$ & $10.1(7.7)$ & $10.7(8.1)$ \\
\hline \multicolumn{4}{|l|}{ DASS-21 Depression Category } \\
\hline Normal & $62(46.3 \%)$ & 99 (52.1\%) & 161 (49.7\%) \\
\hline Mild & $24(17.9 \%)$ & $31(16.3 \%)$ & 55 (17.0\%) \\
\hline Moderate & $33(24.6 \%)$ & $44(23.2 \%)$ & 77 (23.8\%) \\
\hline Severe & $9(6.7 \%)$ & $10(5.3 \%)$ & $19(5.9 \%)$ \\
\hline Extremely severe & $6(4.5 \%)$ & $6(3.2 \%)$ & $12(3.7 \%)$ \\
\hline DASS-21 Anxiety & $6.6(5.9)$ & $5.6(5.1)$ & $6.0(5.5)$ \\
\hline \multicolumn{4}{|l|}{ DASS-21 Anxiety Category } \\
\hline Normal & $83(61.5 \%)$ & $134(70.5 \%)$ & $217(66.8 \%)$ \\
\hline Mild & $11(8.1 \%)$ & $17(8.9 \%)$ & $28(8.6 \%)$ \\
\hline Moderate & $32(23.7 \%)$ & $29(15.3 \%)$ & $61(18.8 \%)$ \\
\hline Severe & $6(4.4 \%)$ & $4(2.1 \%)$ & $10(3.1 \%)$ \\
\hline Extremely severe & $3(2.2 \%)$ & $6(3.2 \%)$ & $9(2.8 \%)$ \\
\hline DASS-21 Stress & $14.9(7.1)$ & $13.7(6.2)$ & $14.2(6.6)$ \\
\hline \multicolumn{4}{|l|}{ DASS-21 Stress Category } \\
\hline Normal & $73(54.1 \%)$ & $117(61.6 \%)$ & $190(58.5 \%)$ \\
\hline Mild & $32(23.7 \%)$ & $34(17.9 \%)$ & $66(20.3 \%)$ \\
\hline Moderate & $21(15.6 \%)$ & $32(16.8 \%)$ & $53(16.3 \%)$ \\
\hline Severe & $7(5.2 \%)$ & $7(3.7 \%)$ & $14(4.3 \%)$ \\
\hline Extremely severe & $2(1.5 \%)$ & $0(0.0 \%)$ & $2(0.6 \%)$ \\
\hline Energy \& Fatigue & $45.8(19.3)$ & $43.9(18.3)$ & $44.7(18.7)$ \\
\hline QoL Physical Health & $47.8(6.7)$ & $46.8(7.4)$ & $47.2(7.2)$ \\
\hline QoL Mental Health & $41.4(10.3)$ & $42.5(10.1)$ & $42.0(10.2)$ \\
\hline
\end{tabular}

Data pooled from the control and Physical Activity and sleep interventions from the pooled from Synergy and Refresh trials 
Table 2 Descriptive statistics of ASI-12 and Sub-component Scores by group and assessment point

\begin{tabular}{|c|c|c|c|c|c|c|c|c|}
\hline & \multicolumn{2}{|l|}{ Baseline } & \multicolumn{3}{|l|}{3 Months } & \multicolumn{3}{|l|}{6 Months } \\
\hline & $\begin{array}{l}\text { Control } \\
(n=135)\end{array}$ & $\begin{array}{l}\text { Intervention } \\
(n=190)\end{array}$ & $\begin{array}{l}\text { Control } \\
(n=112)\end{array}$ & $\begin{array}{l}\text { Intervention } \\
(n=160)\end{array}$ & Group Difference & $\begin{array}{l}\text { Control } \\
(n=96)\end{array}$ & $\begin{array}{l}\text { Intervention } \\
(n=117)\end{array}$ & Group Difference \\
\hline & $M(S D)$ & $M(S D)$ & $M(S D)$ & $M(S D)$ & $d(95 \% \mathrm{Cl})^{\mathrm{a}}$ & $M(S D)$ & $M(S D)$ & $d(95 \% \mathrm{Cl})^{\mathrm{a}}$ \\
\hline ASI-12 Score & $46.83(10.03)$ & $47.83(11.56)$ & $51.99(12.71)$ & $57.89(15.08)$ & $0.42(0.17,0.66)$ & $51.40(12.28)$ & $58.34(14.60)$ & $0.51(0.24,0.78)$ \\
\hline MVPA Frequency Score & $1.00(1.13)$ & $0.91(0.80)$ & $1.42(1.19)$ & $1.69(1.48)$ & $0.19(-0.05,0.43)$ & $1.31(1.10)$ & $1.53(1.31)$ & $0.18(-0.10,0.45)$ \\
\hline RT Frequency Score & $0.28(0.81)$ & $0.55(1.48)$ & $0.84(1.80)$ & $1.47(2.05)$ & $0.32(0.08,0.57)$ & $0.63(1.60)$ & $1.36(2.06)$ & $0.39(0.12,0.66)$ \\
\hline MVPA Intensity Score & $1.65(2.72)$ & $1.78(2.82)$ & $1.99(2.82)$ & $2.13(2.75)$ & $0.05(-0.19,0.29)$ & $1.99(2.79)$ & $2.35(2.91)$ & $0.13(-0.14,0.40)$ \\
\hline Activity Type Score & $5.33(2.04)$ & $5.53(2.46)$ & $5.98(2.40)$ & $7.06(2.88)$ & $0.40(0.16,0.64)$ & $5.78(2.09)$ & $6.84(2.91)$ & $0.41(0.14,0.68)$ \\
\hline MVPA Duration Score & $1.25(1.43)$ & $0.95(0.91)$ & $1.90(1.99)$ & $2.00(1.86)$ & $0.05(-0.19,0.29)$ & $1.99(2.17)$ & $2.12(2.05)$ & $0.06(-0.21,0.33)$ \\
\hline Sitting Duration Score & $3.42(2.06)$ & $3.42(2.27)$ & $3.62(2.28)$ & $3.99(2.26)$ & $0.16(-0.08,0.40)$ & $4.33(2.42)$ & $4.52(2.26)$ & $0.08(-0.19,0.35)$ \\
\hline Sleep Alertness Score & $8.22(2.96)$ & $8.54(2.48)$ & $7.86(3.37)$ & $8.25(2.82)$ & $0.13(-0.11,0.37)$ & $7.43(3.54)$ & $8.75(2.50)$ & $0.44(0.16,0.71)$ \\
\hline Sleep Quality Score & $3.51(1.79)$ & $3.47(1.84)$ & $4.46(2.22)$ & $5.50(2.19)$ & $0.47(0.23,0.72)$ & $4.90(2.21)$ & $5.38(2.43)$ & $0.21(-0.06,0.48)$ \\
\hline Sleep Midpoint Score & $7.33(4.44)$ & $7.42(4.39)$ & $7.68(4.24)$ & $7.25(4.48)$ & $-0.10(-0.34,0.14)$ & $6.46(4.81)$ & $6.75(4.70)$ & $0.06(-0.21,0.33)$ \\
\hline Sleep Timing Score & $5.69(2.32)$ & $5.91(2.14)$ & $5.88(2.20)$ & $6.00(1.77)$ & $0.06(-0.18,0.30)$ & $5.81(2.08)$ & $6.28(1.68)$ & $0.25(-0.02,0.52)$ \\
\hline Sleep Efficiency Score & $6.63(2.12)$ & $6.54(1.80)$ & $6.87(2.18)$ & $7.41(1.92)$ & $0.27(0.03,0.51)$ & 7.03 (1.97) & $7.34(2.01)$ & $0.16(-0.11,0.43)$ \\
\hline Sleep Duration Score & $2.52(4.36)$ & $2.79(4.50)$ & $3.48(4.79)$ & $5.13(5.01)$ & $0.33(0.09,0.58)$ & $3.75(4.87)$ & $5.13(5.02)$ & $0.28(0.01,0.55)$ \\
\hline
\end{tabular}

All table values based on observed observations. 'Between groups differences at assessment point expressed as Cohen's $d$ are presented without adjustment for baseline value

improvements in the activity-sleep index mediated intervention effects on stress symptoms and ratings of energy and fatigue. Improvements in the physical activity-sleep index also mediated improvements in symptoms of depression, anxiety and QOL mental health scores despite no significant intervention effects on each of these outcomes at 3 months. This pattern of results was similar at 6 months. These results indicate that among physically inactive adults who report poor quality sleep, the intervention improved their overall activity and sleep patterns and these improvements in contributed to improvements in indicators of mental health, energy and fatigue observed during the intervention.

Several studies have demonstrated that interventions that improve physical activity or reduce insomnia symptoms can significantly reduce symptoms of depression and anxiety [7, 16, 17, 52-55]. However, few interventions have simultaneously targeted improvements in both physical activity and sleep using dedicated intervention strategies [21, 22, 56]. The current study extends previous research by demonstrating how an intervention improves the overall pattern of activity and sleep health of physically inactive adults with poor sleep and that improvement in the overall activity-sleep pattern mediated improvements in mental health and quality of life. These findings are unique, as the activity-sleep pattern includes multiple dimensions of activity and sleep health, and improvements in the activity-sleep pattern were associated with improved mental health outcomes. The multi-dimensional nature of the index is important, given the evidence that different combinations of activity (i.e., aerobic activity and resistance training) or sleep (i.e., sleep duration and quality) $[13,57]$ influence health in different ways, with better health outcomes typically associated with lower risk combinations of behaviours.

Several mechanisms are thought to link physical activity (i.e., neurophysiological, psychological) and sleep disturbances (i.e., endocrine, cognitive, neuroplasticity and

Table 3 Results of mediation model examining effect of the intervention (baseline to 3 months) on ASI-12 and mental health outcomes at 3 months

\begin{tabular}{llllll}
\hline Outcome & A $(\mathbf{S E})$ & B (SE) & Direct (SE) & C (SE) & AB (SE)[95\%Cl] \\
\hline Depressive Symptoms & $2.99(0.80)^{\mathrm{a}}$ & $-0.10(0.03)^{\mathrm{a}}$ & $-0.25(0.35)$ & $-0.56(0.35)$ & $-0.31(0.12)[-0.60,-0.11]$ \\
Anxiety Symptoms & $3.01(0.80)^{\mathrm{a}}$ & $-0.04(0.02)^{\mathrm{a}}$ & $-0.21(0.22)$ & $-0.32(0.22)$ & $-0.11(0.07)[-0.27,-0.01]$ \\
Stress Symptoms & $2.97(0.80)^{\mathrm{a}}$ & $-0.12(0.02)^{\mathrm{a}}$ & $-0.26(0.30)$ & $-0.63(0.31)^{\mathrm{a}}$ & $-0.37(0.12)[-0.65,-0.17]$ \\
QOL Physical Score & $3.00(0.80)^{\mathrm{a}}$ & $0.02(0.03)$ & $0.28(0.44)$ & $0.36(0.43)$ & $0.07(0.09)[-0.08,0.29]$ \\
QOL Mental Score & $3.02(0.80)^{\mathrm{a}}$ & $0.17(0.04)^{\mathrm{a}}$ & $0.56(0.57)$ & $1.09(0.57)$ & $0.53(0.20)[0.22,1.01]$ \\
Energy \& Fatigue & $3.01(0.80)^{\mathrm{a}}$ & $0.28(0.07)^{\mathrm{a}}$ & $1.15(0.90)$ & $2.00(0.91)^{\mathrm{a}}$ & $0.85(0.33)[0.33,1.63]$ \\
\hline
\end{tabular}

In all models a path adjusted for study (Synergy, REFRESH) and baseline value of mediator, b path adjusted for study (Synergy, REFRESH) and baseline value of mediator and outcome. ${ }^{a}$ indicates $p<0.05$ 
Table 4 Results of mediation model examining effect of the intervention (baseline to 6 months) on ASI-12 and mental health outcomes at 6 months

\begin{tabular}{llllll}
\hline Outcome & A (SE) & B (SE) & Direct (SE) & C (SE) & AB (SE)[95\%Cl] \\
\hline Depressive Symptoms & $3.07(0.92)^{\mathrm{a}}$ & $-0.13(0.03)^{\mathrm{a}}$ & $-0.31(0.43)$ & $-0.71(0.44)$ & $-0.40(0.18)[-0.86,-0.13]$ \\
Anxiety Symptoms & $3.12(0.93)^{\mathrm{a}}$ & $-0.09(0.02)^{\mathrm{a}}$ & $-0.17(0.29)$ & $-0.46(0.30)$ & $-0.29(0.13)[-0.70,-0.12]$ \\
Stress Symptoms & $3.08(0.92)^{\mathrm{a}}$ & $-0.18(0.03)^{\mathrm{a}}$ & $-0.40(0.40)$ & $-0.96(0.43)^{\mathrm{a}}$ & $-0.56(0.21)[-1.08,-0.24]$ \\
QOL Physical Score & $3.00(0.92)^{\mathrm{a}}$ & $0.09(0.04)^{\mathrm{a}}$ & $0.84(0.51)$ & $1.11(0.51)^{\mathrm{a}}$ & $0.27(0.14)[0.08,0.65]$ \\
QOL Mental Score & $3.07(0.92)^{\mathrm{a}}$ & $0.18(0.05)^{\mathrm{a}}$ & $-0.11(0.66)$ & $0.44(0.66)$ & $0.55(0.24)[0.19,1.19]$ \\
Energy \& Fatigue & $3.04(0.92)^{\mathrm{a}}$ & $0.32(0.09)^{\mathrm{a}}$ & $2.50(1.17)^{\mathrm{a}}$ & $3.48(1.18)^{\mathrm{a}}$ & $0.99(0.48)[0.30,2.22]$ \\
\hline
\end{tabular}

In all models a path adjusted for study (Synergy, REFRESH) and baseline value of mediator, b path adjusted for study (Synergy, REFRESH) and baseline value of mediator and outcome. ${ }^{a}$ indicates $p<0.05$

emotional pathways) to symptoms of depression and anxiety [58-60]; these may overlap or act in synergy to explain these findings. This study, however, could not examine the mechanisms responsible for the observed associations. The mediated effects of the intervention on mental health outcomes were larger for depressive symptoms than they were for anxiety. This is consistent with evidence of the effect of physical activity interventions on depression and anxiety [16, 17, 52], and contrary to the prospective association between insomnia symptoms and depression and anxiety [60]. These seemingly contrasting results may reflect overlapping mechanistic pathways linking physical activity and sleep with mental health and the fact that the current study examined the influence of a combined activity-sleep index rather than either behaviour separately [58-60]. Alternatively, it may reflect that the larger differences in physical activity between the intervention and control groups in the current study in comparison with the differences in sleep.

As the DASS-21 classifications are not diagnostic, the effect of improving overall activity and sleep patterns on clinical symptom severity is unknown [61]. However, the majority of participants reported normal to mild symptom severity at baseline and improvements in the activity-sleep index mediated improvements in symptom severity [61]. This is a useful finding, as even sub-clinical levels of depression and anxiety can adversely affect well-being $[62,63]$. Depression, anxiety and insomnia or sleep disturbance frequently co-occur [64-66], and individuals with depression and anxiety are less active than those without these conditions [67]. Examination of comorbid depression and anxiety was beyond the scope of the current study, but would provide useful insights, as people with these chronic conditions are frequently excluded from interventions [68]. It is unclear what magnitude of improvement in the novel activity-sleep index is clinically meaningful. The exploratory analyses which compared the activity-sleep index scores of people who did or did not report improvements in their depression, anxiety and stress symptoms aimed to provide some insight into this. People who improved their depression or stress symptoms had higher ASI-12 scores than those who did not improve or remained stable $(\mathrm{d}=0.25-0.29$, Supplementary Table 7). These results require replication in a sample with a greater range of symptom severity and comparison with meaningful changes from the participant's perspective. All outcomes examined in the current study were mental health outcomes except QOL-Physical functioning, which demonstrated both inconsistent mediation effects and intervention effects. In light of this, and the different biological mechanisms that link physical activity and sleep to physical health and mental health outcomes [3, 58, 59, 69], there is a need for more research examining the effect of the overall pattern of physical activity and sleep on physical and mental health outcomes.

Limitations of the study include the reliance on selfreport measures of physical activity, sitting time and sleep, which are subject to recall bias. Objective monitoring of physical activity, sitting time and sleep using accelerometery would help to overcome. Accelerometers are useful for assessing sleep duration and timing [70], however, are unable to capture the restorative effects of sleep, which may be important for health and wellbeing. Similarly, the utility of accelerometers for assessing resistance training is limited and therefore, a combined approach is likely to be useful in future studies. The presence of undiagnosed sleep conditions (i.e., insomnia, sleep apnoea) or mental health conditions (i.e., depression, anxiety) was not assessed, so it is unclear whether these influenced the results of the current study. Multiple methods exist to combine multiple variables measured on different scales, time frames and measuring different behaviours. These methods include creating summative scores, combining standardised scores, various weighting approaches $[9,42,43]$, and the use of compositional data analysis for time-based metrics [7]. The current study used a simple method to summarise the separate dimensions, but did not weight the dimensions prior to summarising them and did not examine the separate dimensions as potential mediators. The ASI 
is an overall score that is simple to derive, and allows multiple dimensions measured on different scales (i.e., time, frequency, or ratings) to be aggregated. Comparing different approaches to creating an overall activity-sleep index, including refining which dimensions are included, will provide greater insight into how physical activity and sleep jointly influence health. Results were based on secondary analyses of pooled data from two RCTs, consequently the current study was not specifically designed to examine how changes in activity-sleep behaviour mediated intervention effects on the outcomes examined. Additionally, the age range of participants was 18-64, although they were predominantly middle aged (Table 1 ), so the results are only applicable to young and mid-age adults. Participant age ranges were delimited (Synergy: 18-54 years; Refresh: 45-64) due to study design (e.g., Refresh targeting mid age adults) and pragmatic reasons (e.g., changes in sleep at older ages, different activity/ guidelines for adults $65+$ ).

In conclusion, a multiple behaviour m-health intervention that targeted physical activity and sleep with specific intervention strategies significantly improved the overall pattern of physical activity and sleep health in physically inactive adults who reported poor sleep. Furthermore, improvements in activity-sleep patterns mediated the effects of the intervention on mental health and quality of life. Interventions that create more favourable activitysleep patterns could be useful for improving mental health and quality of life.

\section{Supplementary Information}

The online version contains supplementary material available at https://doi. org/10.1186/s12966-021-01112-z.

\section{Additional file 1.}

\section{Acknowledgements}

Not applicable.

\begin{abstract}
Authors' contributions
MJD conceptualised the current study. MJD, ATR, and EGH devised the analysis plan. MJD conducted the analyses. MJD and ATR wrote the first draft of the manuscript. ATR and BM collected the data in each of trials. MJD, ATR, WJB, CV, BM, RCP conceptualised the Synergy study, MJD, ATR, EGH, WJB, CV, $B M, R C P$ conceptualised the Refresh study. MJD, ATR, EGH, WJB, CV, BM, RCP contributed to data interpretation and critically reviewed, edited and approved the final manuscript.

\section{Funding}

MJD is supported by a Career Development Fellowship (APP1141606) from the National Health and Medical Research Council. ATR was supported by a Wests Scholarship during this research (ID G1201152). This project was supported in part by a Vanguard Grant (ID 100629) and a Future Leader Fellowship awarded to MJD (ID 100029) from the National Heart Foundation of Australia. CV (ID 100427) was supported by Future Leader Fellowship from the National Heart Foundation of Australia during this research. No funding body played any role in the design or conduct of the studies or reporting of results.
\end{abstract}

\section{Availability of data and materials}

The datasets used and analysed during the current study are available from the corresponding authors on reasonable request. A public version of the Balanced app with slightly modified functionality relative to what is described in the current manuscript is available from iTunes Store (iOS) and Android Play. Content of the public version may change/ be updated over time.

\section{Declarations}

\section{Ethics approval and consent to participate}

All procedures performed in studies involving human participants were in accordance with the ethical standards of the institutional and/or national research committee and with the 1964 Helsinki declaration and its later amendments or comparable ethical standards Informed consent was obtained from all individual participants included in the study. Approval was provided by the University of Newcastle Human Research Ethics Committee: H-2016-0267; H-2016-0181.

\section{Consent for publication}

Not applicable.

\section{Competing interests}

MJD, ATR, EGH, WJB, CV, BM, RCP declare they have no competing interests.

\section{Author details}

${ }^{1}$ School of Medicine \& Public Health; Faculty of Health and Medicine, Priority Research Centre for Physical Activity and Nutrition, The University of Newcastle, University Drive, Callaghan, NSW 2308, Australia. ${ }^{2}$ Priority Research Centre for Physical Activity and Nutrition, The University of Newcastle, University Drive, Callaghan, NSW 2308, Australia. ${ }^{3}$ School of Education, University of Newcastle, Callaghan, NSW 2308, Australia. ${ }^{4}$ School of Human Movement and Nutrition Sciences, The University of Queensland, St Lucia, QLD 4072, Australia. ${ }^{5}$ Physical Activity Research Group, School for Health, Medical and Applied Sciences, Central Queensland University, Rockhampton, Queensland, Australia.

Received: 17 November 2020 Accepted: 12 March 2021

Published online: 25 March 2021

\section{References}

1. Warburton DER, Bredin SSD. Health benefits of physical activity: a systematic review of current systematic reviews. Curr Opin Cardiol. 2017;32(5):541-56. https://doi.org/10.1097/HCO.0000000000000437.

2. Ekelund U, Steene-Johannessen J, Brown WJ, Fagerland MW, Owen N, Powell K, et al. Does physical activity attenuate, or even eliminate the detrimental association of sitting time with mortality? A harmonised metaanalysis of data from more than one million men and women. Lancet. 2016; 388:1302-10.

3. St-Onge M-P, Grandner MA, Brown D, Conroy MB, Jean-Louis G, Coons M, et al. Sleep duration and quality: impact on lifestyle behaviors and cardiometabolic health. Circulation. 2016;134:e367-86.

4. Xiao Q, Keadle SK, Hollenbeck AR, Matthews CE. Sleep duration and total and cause-specific mortality in a large US cohort: interrelationships with physical activity, sedentary behavior, and body mass index. Am J Epidemiol. 2014;180(10):997-1006. https://doi.org/10.1093/aje/kwu222.

5. Duncan MJ, Oftedal S, Rebar AL, Murawski B, Short CE, Rayward AT, Vandelanotte C. Patterns of physical activity, sitting time, and sleep in Australian adults: a latent class analysis. Sleep Health. 2020;6(6):828-34. https://doi.org/10.1016/j.sleh.2020.04.006.

6. Rayward AT, Duncan MJ, Brown WJ, Plotnikoff RC, Burton NW. A crosssectional cluster analysis of the combined association of physical activity and sleep with sociodemographic and health characteristics in mid-aged and older adults. Maturitas. 2017;102:56-61.

7. Dumuid D, Stanford TE, Martin-Fernández JA, Pedišić Ž, Maher CA, Lewis LK, Hron K, Katzmarzyk PT, Chaput JP, Fogelholm M, Hu G, Lambert EV, Maia J, Sarmiento OL, Standage M, Barreira TV, Broyles ST, Tudor-Locke C, Tremblay MS, Olds T. Compositional data analysis for physical activity, sedentary time and sleep research. Stat Methods Med Res. 2018;27(12):3726-38. https://doi. org/10.1177/0962280217710835. 
8. Rosenberger ME, Fulton JE, Buman MP, Troiano RP, Grandner MA, Buchner DM, et al. The 24-hour activity cycle: a new paradigm for physical activity. Med Sci Sports Exerc. 2019;51(3):454-64. https://doi.org/10.1249/MSS. 0000000000001811.

9. Keadle SK, Kravitz ES, Matthews CE, Tseng M, Carroll RJ. Development and testing of an integrated score for physical behaviors. Med Sci Sports Exerc. 2019;51(8):1759-66. https://doi.org/10.1249/MSS.0000000000001955.

10. Wennman H, Kronholm E, Heinonen OJ, Kujala UM, Kaprio J, Partonen T, Bäckmand H, Sarna S, Borodulin K. Leisure time physical activity and sleep predict mortality in men irrespective of background in competitive sports. Progress Prevent Med. 2017;2(6):e0009. https://doi.org/10.1097/pp9. 0000000000000009.

11. Buysse DJ. Sleep health: can we define it? Does it matter? Sleep. 2014;37(1): 9-17. https://doi.org/10.5665/sleep.3298.

12. Stamatakis E, Lee IM, Bennie J, Freeston J, Hamer M, O'Donovan G, et al. Does strength-promoting exercise confer unique health benefits? A pooled analysis of data on 11 population cohorts with all-cause, Cancer, and cardiovascular mortality endpoints. Am J Epidemiol. 2018;187(5):1102-12. https://doi.org/10.1093/aje/kwx345.

13. Hoevenaar-Blom MP, Spijkerman AM, Kromhout D, van den Berg JF, Verschuren WM. Sleep duration and sleep quality in relation to 12-year cardiovascular disease incidence: the MORGEN study. Sleep. 2011;34(11): 1487-92. https://doi.org/10.5665/sleep.1382

14. Bennie JA, De Cocker K, Biddle SJH, Teychenne MJ. Joint and dosedependent associations between aerobic and muscle-strengthening activity with depression: a cross-sectional study of 1.48 million adults between 2011 and 2017. Depress Anxiety. 2020;37(2):166-78. https://doi. org/10.1002/da.22986.

15. Oftedal S, Smith J, Vandelanotte C, Burton NW, Duncan MJ. Resistance training in addition to aerobic activity is associated with lower likelihood of depression and comorbid depression and anxiety symptoms: a cross sectional analysis of Australian women. Prev Med. 2019;126:105773. https:// doi.org/10.1016/j.ypmed.2019.105773.

16. Gordon BR, McDowell CP, Hallgren M, Meyer JD, Lyons M, Herring MP. Association of Efficacy of resistance exercise training with depressive symptoms: meta-analysis and meta-regression analysis of randomized clinical trials. JAMA Psychiatry. 2018;75(6):566-76. https://doi.org/10.1001/ja mapsychiatry.2018.0572.

17. Gordon BR, McDowell CP, Lyons M, Herring MP. The effects of resistance exercise training on anxiety: a meta-analysis and meta-regression analysis of randomized controlled trials. Sports Med. 2017:47(12):2521-32. https://doi. org/10.1007/s40279-017-0769-0

18. Rhodes RE, Janssen I, Bredin SSD, Warburton DER, Bauman A. Physical activity: health impact, prevalence, correlates and interventions. Psychol Health. 2017:32(8):942-75. https://doi.org/10.1080/08870446.2017.1325486.

19. van der Zweerde T, Bisdounis L, Kyle SD, Lancee J, van Straten A. Cognitive behavioral therapy for insomnia: a meta-analysis of long-term effects in controlled studies. Sleep Med Rev. 2019;48:101208. https://doi.org/10.1016/j. smrv.2019.08.002.

20. Mitchell LJ, Bisdounis L, Ballesio A, Omlin X, Kyle SD. The impact of cognitive behavioural therapy for insomnia on objective sleep parameters: a meta-analysis and systematic review. Sleep Med Rev. 2019;47:90-102. https://doi.org/10.1016/j.smrv.2019.06.002.

21. Murawski B, Plotnikoff RC, Rayward AT, Oldmeadow C, Vandelanotte C, Brown WJ, Duncan MJ. Efficacy of an m-health physical activity and sleep health intervention for adults: a randomized waitlist-controlled trial. Am J Prev Med. 2019;57(4):503-14. https://doi.org/10.1016/j.amepre.2019.05.009.

22. Rayward AT, Murawski B, Duncan MJ, Holliday EG, Vandelanotte C, Brown WJ, Plotnikoff RC. Efficacy of an $\mathrm{m}$-health physical activity and sleep intervention to improve sleep quality in middle-aged adults: the Refresh study randomized controlled trial. Ann Behav Med. 2020;54(7):470-83. https://doi.org/10.1093/abm/kaz064

23. Petrov ME, Hasanaj K, Hoffmann CM, Epstein DR, Krahn L, Park JG, Hollingshead K, Yu TY, Todd M, St. Louis EK, Morgenthaler TI, Buman MP. Rationale, design, and development of SleepWell24: a smartphone application to promote adherence to positive airway pressure therapy among patients with obstructive sleep apnea. Contemp Clin Trials. 2020;89: 105908. https://doi.org/10.1016/j.cct.2019.105908.

24. Logue EE, Bourguet CC, Palmieri PA, Scott ED, Matthews BA, Dudley P, et al. The better weight-better sleep study: a pilot intervention in primary care. Am J Health Behav. 2012;36(3):319-34.
25. Duncan MJ, Fenton S, Brown WJ, Collins CE, Glozier N, Kolt GS, Holliday E, Morgan P, Murawski B, Plotnikoff R, Rayward A, Stamatakis E, Vandelanotte C, Burrows T. Efficacy of a multi-component $\mathrm{m}$-health weight-loss intervention in overweight and obese adults: a randomised controlled trial. Int J Environ Res Public Health. 2020;17(17):6200. https://doi.org/10.3390/ ijerph17176200.

26. Murawski B, Plotnikoff RC, Rayward AT, et al. Randomised controlled trial using a theory-based $\mathrm{m}$-health intervention to improve physical activity and sleep health in adults: the Synergy Study protocol. BMJ Open. 2018;8: e018997. https://doi.org/10.1136/bmjopen-2017-018997.

27. Rayward AT, Murawski B, Plotnikoff RC, Vandelanotte C, Brown WJ, Holliday EG, Duncan MJ. A randomised controlled trial to test the efficacy of an $\mathrm{m}$ health delivered physical activity and sleep intervention to improve sleep quality in middle-aged adults: the Refresh study protocol. Contemp Clin Trials. 2018;73:36-50. https://doi.org/10.1016/j.cct.2018.08.007.

28. Sterne JAC, Savović J, Page MJ, Elbers RG, Blencowe NS, Boutron I, et al. RoB 2: a revised tool for assessing risk of bias in randomised trials. BMJ. 2019;366:14898.

29. Michie S, Richardson M, Johnston M, Abraham C, Francis J, Hardeman W. The behavior change technique taxonomy (v1) of 93 hierarchically clustered techniques: building an international consensus for the reporting of behavior change interventions. Ann Behav Med. 2013;46(1):81-95. https:// doi.org/10.1007/s12160-013-9486-6.

30. Bandura A. The primacy of self-regulation in health promotion. Appl Psychol Health Well Being. 2005:54:245-54.

31. Brown WJ, Bauman A, Chey T, Trost S, Mummery K. Comparison of surveys used to measure physical activity. Aust N Z J Public Health. 2004;28(2):12834. https://doi.org/10.1111/j.1467-842X.2004.tb00925.x

32. Brown WJ, Bauman A, Trost S, Mummery WK, Owen N. Test-retest reliability of four physical activity measures used in population surveys. J Sci Med Sport. 2004;7(2):205-15. https://doi.org/10.1016/S1440-2440(04)80010-0.

33. Brown WJ, Burton NW, Marshall AL, Miller YD. Reliability and validity of a modified self-administered version of the active Australia physical activity survey in a sample of mid-age women. Aust N Z J Public Health. 2008;32(6): 535-41. https://doi.org/10.1111/j.1753-6405.2008.00305.x.

34. Vandelanotte C, Duncan MJ, Stanton R, Rosenkranz RR, Caperchione CM, Rebar AL, Savage TN, Mummery WK, Kolt GS. Validity and responsiveness to change of the active Australia survey according to gender, age, BMI, education, and physical activity level and awareness. BMC Public Health. 2019;19(1):407. https://doi.org/10.1186/s12889-019-6717-1.

35. Chau JY, van der Ploeg HP, Dunn S, Kurko J, Bauman AE. A tool for measuring workers' sitting time by domain: the workforce sitting questionnaire. Br J Sports Med. 2011;45(15):1216-22. https://doi.org/10.1136/ bjsports-2011-090214.

36. Buysse DJ, Reynolds CF 3rd, Monk TH, Berman SR, Kupfer DJ. The Pittsburgh sleep quality index: a new instrument for psychiatric practice and research. Psychiatry Res. 1989;28(2):193-213. https://doi.org/10.1016/0165-1781 (89)90047-4

37. Mollayeva T, Thurairajah P, Burton K, Mollayeva S, Shapiro CM, Colantonio A. The Pittsburgh sleep quality index as a screening tool for sleep dysfunction in clinical and non-clinical samples: a systematic review \& meta-analysis. Sleep Med Rev. 2016;25:52-73. https://doi.org/10.1016/j.smrv.2015.01.009.

38. Mastin DF, Bryson J, Corwyn R. Assessment of sleep hygiene using the sleep hygiene index. J Behav Med. 2006;29(3):223-7. https://doi.org/10.1007/s1 0865-006-9047-6.

39. DeSantis AS, Dubowitz T, Ghosh-Dastidar B, Hunter GP, Buman M, Buysse DJ, et al. A preliminary study of a composite sleep health score: associations with psychological distress, body mass index, and physical functioning in a low-income African American community. Sleep Health. 2019;5(5):514-20. https://doi.org/10.1016/j.sleh.2019.05.001.

40. Brandolim Becker N, Martins RIS, Jesus SN, Chiodelli R, Stephen RM. Sleep health assessment: a scale validation. Psychiatry Res. 2018;259:51-5. https:// doi.org/10.1016/j.psychres.2017.10.014.

41. Brindle RC, Yu L, Buysse DJ, Hall MH. Empirical derivation of cutoff values for the sleep health metric and its relationship to cardiometabolic morbidity: results from the Midlife in the United States (MIDUS) study. Sleep. 2019; 42(9):zsz116.

42. Drake BF, Quintiliani LM, Sapp AL, Li Y, Harley AE, Emmons KM, Sorensen G. Comparing strategies to assess multiple behavior change in behavioral intervention studies. Transl Behav Med. 2013;3(1):114-21. https://doi.org/10.1 007/s13142-013-0195-2. 
43. Prochaska JJ, Prochaska JM, Prochaska JO. Building a science for multiplerisk behavior change. In: Riekert KA, Ockene JK, Pbert L, editors. The handbook of health behavior change. 4th ed. New York: Springer Publishing Company; 2013

44. Giannoulis C. The Analysis Factor: Rescaling Sets of Variables to be on the Same Scale. 2020 [Internet Archive. Web. 16 Nov. 2020]. Available from: https://www.theanalysisfactor.com/rescaling-variables-to-be-same/ ; http://a rchive.today/qjLpy.

45. Lovibond PF, Lovibond SH. The structure of negative emotional states: comparison of the depression anxiety stress scales (DASS) with the Beck depression and anxiety inventories. Behav Res Ther. 1995;33(3):335-43. https://doi.org/10.1016/0005-7967(94)00075-U.

46. Henry JD, Crawford JR. The short-form version of the depression anxiety stress scales (DASS-21): construct validity and normative data in a large nonclinical sample. Brit J Clin Psychol. 2005:44(Pt 2):227-39. https://doi.org/1 0.1348/014466505X29657.

47. Ware J Jr, Kosinski M, Keller SD. A 12-item Short-form health survey: construction of scales and preliminary tests of reliability and validity. Med Care. 1996;34(3):220-33. https://doi.org/10.1097/00005650-199603000-00003.

48. Busija L, Pausenberger E, Haines TP, Haymes S, Buchbinder R, Osborne RH. Adult measures of general health and health-related quality of life: Medica Outcomes Study Short Form 36-Item (SF-36) and Short Form 12-Item (SF12) Health Surveys, Nottingham Health Profile (NHP), Sickness Impact Profile (SIP), Medical Outcomes Study Short Form 6D (SF-6D), Health Utilities Index Mark 3 (HUI3), Quality of Well-Being Scale (QWB), and Assessment of Quality of Life (AQOL). Arthritis Care Res. 2011;63(S11):S383-412.

49. Ware JE, Sherbourne CD. The MOS 36-item Short-form health survey (SF-36). Med Care. 1992;30(6):473-83. https://doi.org/10.1097/00005650-1 99206000-00002.

50. Cohen J. Statistical power analysis for the behavioral sciences: Academic Press; 2013. https://doi.org/10.4324/9780203771587.

51. Fairchild AJ, McDaniel HL. Best (but oft-forgotten) practices: mediation analysis. Am J Clin Nutr. 2017;105(6):1259-71. https://doi.org/10.3945/a jen.117.152546.

52. Rebar AL, Stanton R, Geard D, Short C, Duncan MJ, Vandelanotte C. A metameta-analysis of the effect of physical activity on depression and anxiety in non-clinical adult populations. Health Psychol Rev. 2015;9(3):366-78. https:// doi.org/10.1080/17437199.2015.1022901.

53. Christensen $H$, Batterham PJ, Gosling JA, Ritterband LM, Griffiths KM, Thorndike FP, Glozier N, O'Dea B, Hickie IB, Mackinnon AJ. Effectiveness of an online insomnia program (SHUTi) for prevention of depressive episodes (the GoodNight study): a randomised controlled trial. Lancet Psychiatry. 2016;3(4):333-41. https://doi.org/10.1016/S2215-0366(15)00536-2.

54. Espie CA, Emsley R, Kyle SD, Gordon C, Drake CL, Siriwardena AN, Cape J, Ong JC, Sheaves B, Foster R, Freeman D, Costa-Font J, Marsden A, Luik Al. Effect of digital cognitive behavioral therapy for insomnia on health, psychological well-being, and sleep-related quality of life: a randomized clinical trial. JAMA Psychiatry. 2019;76(1):21-30. https://doi.org/10.1001/jama psychiatry.2018.2745

55. Luik Al, Bostock S, Chisnall L, Kyle SD, Lidbetter N, Baldwin N, Espie CA. Treating depression and anxiety with digital cognitive Behavioural therapy for insomnia: a real world NHS evaluation using standardized outcome measures. Behav Cogn Psychother. 2017;45(1):91-6. https://doi.org/10.1017/ S1352465816000369.

56. Meader N, King K, Wright K, Graham HM, Petticrew M, Power C, White M, Sowden AJ. Multiple risk behavior interventions: meta-analyses of RCTs. Am J Prev Med. 2017;53(1):e19-30. https://doi.org/10.1016/j.amepre.2017.01.032.

57. Lallukka T, Sivertsen B, Kronholm E, Bin YS, Øverland S, Glozier N. Association of sleep duration and sleep quality with the physical, social, and emotional functioning among Australian adults. Sleep Health. 2018; 4:194-200.

58. Fang H, Tu S, Sheng J, Shao A. Depression in sleep disturbance: a review on a bidirectional relationship, mechanisms and treatment. J Cell Mol Med. 2019;23(4):2324-32. https://doi.org/10.1111/jcmm.14170.

59. Schuch FB, Vancampfort D, Firth J, Rosenbaum S, Ward PB, Silva ES, Hallgren M, Ponce de Leon A, Dunn AL, Deslandes AC, Fleck MP, Carvalho AF, Stubbs B. Physical activity and incident depression: a meta-analysis of prospective cohort studies. Am J Psychiatry. 2018;175(7):631-48. https://doi.org/10.11 76/appi.ajp.2018.17111194.

60. Hertenstein E, Feige B, Gmeiner T, Kienzler C, Spiegelhalder K, Johann A, Jansson-Fröjmark M, Palagini L, Rücker G, Riemann D, Baglioni C. Insomnia as a predictor of mental disorders: a systematic review and meta-analysis. Sleep Med Rev. 2019;43:96-105. https://doi.org/10.1016/j.smrv.2018.10.006.

61. Parkitny L, McAuley J. The depression anxiety stress scale (DASS). J Phys. 2010:56(3):204.

62. Cuijpers P, Vogelzangs N, Twisk J, Kleiboer A, Li J, Penninx BW. Differential mortality rates in major and subthreshold depression: meta-analysis of studies that measured both. Br J Psychiatry. 2013;202(1):22-7. https://doi. org/10.1192/bjp.bp.112.112169.

63. Haller H, Cramer H, Lauche R, Gass F, Dobos GJ. The prevalence and burden of subthreshold generalized anxiety disorder: a systematic review. BMC Psychiatry. 2014;14(1):128. https://doi.org/10.1186/1471-244X-14-128.

64. Brown TA, Campbell LA, Lehman CL, Grisham JR, Mancill RB. Current and lifetime comorbidity of the DSM-IV anxiety and mood disorders in a large clinical sample. J Abnorm Psychol. 2001;110(4):585-99. https://doi.org/10.103 7/0021-843X.110.4.585.

65. Ohayon MM. Prevalence and comorbidity of sleep disorders in general population. Revue du Praticien. 2007;57(14):1521-8.

66. Malhi GS, Bassett D, Boyce P, Bryant R, Fitzgerald PB, Fritz K, Hopwood M, Lyndon B, Mulder R, Murray G, Porter R, Singh AB. Royal Australian and new Zealand College of Psychiatrists clinical practice guidelines for mood disorders. Aust New Zealand J Psychiatry. 2015;49(12):1087-206. https://doi. org/10.1177/0004867415617657.

67. Vancampfort D, Firth J, Schuch FB, Rosenbaum S, Mugisha J, Hallgren M, Probst M, Ward PB, Gaughran F, de Hert M, Carvalho AF, Stubbs B. Sedentary behavior and physical activity levels in people with schizophrenia, bipolar disorder and major depressive disorder: a global systematic review and meta-analysis. World Psychiatry. 2017;16(3):308-15. https://doi.org/10.1002/wps.20458.

68. Bond G, Stanton R, Wintour S-A, Rosenbaum S, Rebar AL. Do exercise trials for adults with depression account for comorbid anxiety? A systematic review. Ment Health Phys Act. 2020;18:100320.

69. Schuch FB, Stubbs B, Meyer J, Heissel A, Zech P, Vancampfort D, Rosenbaum S, Deenik J, Firth J, Ward PB, Carvalho AF, Hiles SA. Physical activity protects from incident anxiety: a meta-analysis of prospective cohort studies. Depress Anxiety. 2019;36(9):846-58. https:/doi.org/10.1002/da.22915.

70. Smith MT, McCrae CS, Cheung J, Martin JL, Harrod CG, Heald JL, et al. Use of Actigraphy for the evaluation of sleep disorders and circadian rhythm sleep-wake disorders: an American Academy of sleep medicine clinical practice guideline. J Clin Sleep Med. 2018;14(7):1231-7. https://doi.org/10. 5664/jcsm.7230

\section{Publisher's Note}

Springer Nature remains neutral with regard to jurisdictional claims in published maps and institutional affiliations.

\section{Ready to submit your research? Choose BMC and benefit from:}

- fast, convenient online submission

- thorough peer review by experienced researchers in your field

- rapid publication on acceptance

- support for research data, including large and complex data types

- gold Open Access which fosters wider collaboration and increased citations

- maximum visibility for your research: over $100 \mathrm{M}$ website views per year

At BMC, research is always in progress.

Learn more biomedcentral.com/submissions 